\title{
A MEDIAÇÃO NO NOVO CÓDIGO DE PROCESSO CIVIL BRASILEIRO: UMA \\ ANÁLISE CRÍTICA DA CIDADANIA PELA BUSCA DO MODELO DE CONSTITUCIONALISMO CONTEMPORÂNEO LATINO-AMERICANO E EUROPEU DEMOCRÁTICO
}

${ }^{1}$ Sérgio Henriques Zandona Freitas

${ }^{2}$ Gabriela Oliveira Freitas

\section{RESUMO}

$\mathrm{O}$ presente artigo aborda o instituto da mediação, incluída no ordenamento jurídico brasileiro pelo Novo Código de Processo Civil. A análise dessa solução consensual de conflitos é realizada pela processualidade democrática e lógica crítica, na Teoria do Processo Constitucional Contemporâneo, como instituição linguística-jurídica, garantidora da cidadania. Assim, aborda-se o instituto cidadania no Estado Democrático de Direito, observado o modelo de Constituições latino-americanas e europeias. Utiliza-se pesquisa bibliográfica e método dedutivo, pela perspectiva macro para concepção micro analítica do tema estudado e, por fim, o procedimento técnico analítico-temático, teórico-interpretativo, buscando solução para questão destacada.

Palavras-chave: Mediação, Cidadania, Estado democrático de direito, Constitucionalismo contemporâneo latino-americano e europeu democrático

\section{MEDIACIÓN EN EL NUEVO CÓDIGO DE PROCEDIMIENTO CIVIL BRASIL: ANÁLISIS CRÍTICO DE LA NACIONALIDAD DE LA BÚSQUEDA DE MODELOS CONSTITUCIONALISMO CONTEMPORÁNEO LATINOAMERICANO Y DEMOCRACIA EUROPEA}

\section{RESUMEN}

El artículo aborda la mediación, incluido en la legislación brasileña por Nueva CPC. El análisis de esta resolución de conflictos de mutuo acuerdo se lleva a cabo por procesualidad democrática y la lógica crítica, Teoría del Proceso Constitucional Contemporáneo como institución jurídico-lingüística, garante de la ciudadanía. Por lo tanto, se acerca instituto de la ciudadanía en un Estado democrático, patrón observado de las constituciones latinoamericanas y europeas. Bibliografía utilizada y el método deductivo, las perspectivas macro para la concepción analítica micro del tema estudiado y, por último, procedimiento técnico analítico-temático, teórico e interpretativo, buscando solución a las cuestiones pendientes.

Palabras-claves: Mediación, Ciudadanía, Estado democrático de derecho, Constitucionalismo contemporáneo latinoamericano y europeo democrático

\footnotetext{
${ }^{1}$ Doutor em Direito pela Pontifícia Universidade Católica - PUC, Belo Horizonte, Minas Gerais, Brasil. Assessor Judiciário do Tribunal de Justiça do Estado de Minas Gerais, Brasil. E-mail: sergiohzf@fumec.br (Brasil)

${ }^{2}$ Doutoranda em Direito pela Pontifícia Universidade Católica - PUC, Belo Horizonte, Minas Gerais, Brasil. Professora de Disciplinas de Direito Processual em Cursos de Graduação e Pós-Graduação em Direito. E-mail: freitasgaby@hotmail.com (Brasil)
} 


\section{INTRODUÇÃO}

Em 16 de março de 2015, foi sancionado e promulgado o novo Código de Processo Civil brasileiro (Lei $\mathrm{n}^{\circ}$ 13.105/2015), depois de uma longa atividade legislativa, com a participação de diversos juristas brasileiros e também dos outros interessados, por meio de diversas audiências públicas. A redação inicial do Projeto, de autoria do Senador José Sarney, que primeiramente tramitou no Senado Federal (Projeto de Lei no 166/2010), é resultado do trabalho de uma Comissão de Juristas, nomeada no mês de setembro de 2009, presidida pelo Ministro Luiz Fux (Supremo Tribunal Federal).

$\mathrm{Na}$ apresentação do Anteprojeto desse texto legislativo brasileiro, foi apresentada uma Exposição de Motivos, em que foram traçadas as diretrizes da pretendida mudança, constando, logo em sua frase inicial, a necessidade de reforma do sistema processual, a fim de proporcionar à sociedade o reconhecimento e a realização dos direitos, ameaçados ou violados, que têm cada um dos jurisdicionados, buscando harmonia com as garantias constitucionais de um Estado Democrático de Direito.

A necessidade de uma nova legislação processual foi justificada na Exposição de Motivos de seu Anteprojeto, pelo suposto objetivo de alcançar a -harmonia da lei ordinária em relação à Constituição Federal da Repúblicall (BRASIL, 2015), para que o processo fique mais adequado aos meio de concretização dos direitos fundamentais previstos no Constitucionalismo contemporâneo: neoconstitucionalismo, garantismo e o modelo de Constituições latino-americanas e europeias democráticas. A partir dessa função autoproclamada pela nova legislação é que os institutos por ela abordados devem ser analisados, a fim de se verificar se tal texto, de fato, direciona-se à concretização do mencionado modelo de Estado.

Assim, opta-se, no presente trabalho científico, pela discussão acerca da mediação, modalidade alternativa de solução de conflitos, incluída pelo novo texto processual como parte obrigatória dos procedimentos cíveis.

Pretende-se analisar se a mediação, no sistema processual em que foi incluída, atinge seus objetivos de resolver alternativamente os conflitos, garantindo o exercício dos direitos fundamentais e, notadamente, o exercício da cidadania, tal como proposto pelo texto da referida Exposição de Motivos. Para tanto, será analisada a mediação, seu conceito e sua utilização no novo CPC, seguindo-se de uma análise do instituto da 
isonomia processual, buscando demonstrar sua imprescindibilidade para a realização da mediação. Por fim, demonstrar-se-á como a mediação, tal como prevista no novo CPC brasileiro, inobserva a cidadania, sendo, por isso, inadequada ao Estado Democrático de Direito e o modelo de Constituições latino-americanas e europeias democráticas.

Para o presente estudo, utiliza-se a pesquisa bibliográfica e o método dedutivo, partindo-se de uma perspectiva macro para uma concepção micro analítica acerca do tema ora em estudo e, por fim, como procedimento técnico a análise temática, teórica e interpretativa, buscando sugestão para a solução da questão destacada.

\section{A MEDIAÇÃo NO NOVO CÓDIGO DE PROCESSO CIVIL BRASILEIRO}

Inicialmente, tem-se por necessário compreender o instituto da mediação, que, segundo Ronaldo Brêtas de Carvalho Dias e Carlos Henrique Soares, -se constitui na participação de um terceiro que não possui poder de decisãol, devendo, assim, —orientar as partes no sentido de uma composição\| (SOARES; BRÊTAS, 2011, p. 6).

Comenta Vezzulla que

[...] mediação é a técnica privada de solução de conflitos que vem demonstrando, no mundo, sua grande eficiência nos conflitos interpessoais, pois com ela, são as próprias partes que acham as soluções. O mediador somente as ajuda a procurá-las, introduzindo, com suas técnicas, os critérios e os raciocínios que lhes permitirão um entendimento melhor. (VEZULLA, 1998, p. 15-16).

Percebe-se que, na mediação, há atuação de um terceiro, sem poder decisório, com capacidade, somente, para conduzir o diálogo entre as partes, conforme esclarecem Leonardo Carneiro da Cunha e João Luiz Lessa de Azevedo Neto:

\footnotetext{
O distanciamento do julgador e o formalismo típico das audiências judiciais, nas quais as partes apenas assistem ao desenrolar dos acontecimentos, falando apenas quando diretamente questionadas em um interrogatório com o objetivo de obter sua confissão, são substituídos pelo debate franco e aberto, com uma figura que pretende facilitar o diálogo [...] (CUNHA; AZEVEDO NETO, 2014, p. 197).
}

O novo Código de Processo Civil (BRASIL, 2015), ao tratar da inafastabilidade da jurisdição, em seu artigo $3^{\circ}$, já informa que é função do Estado promover a solução consensual de conflitos, acrescentando que os métodos de solução de conflitos, notadamente a conciliação e a mediação, -deverão ser estimulados por juízes, advogados, defensores públicos e membros do Ministério Público, inclusive no curso do processo judicialll (art. $3^{\circ}, \S 3^{\circ}$ ).

Percebe-se que o novo Código trata os meios alternativos de solução de conflitos como medida obrigatória, com a clara finalidade de descongestionar o Judiciário e não 
de efetivar os direitos postulados pelas partes, finalidade que deve ser buscada pela Jurisdição. Assim, prevê o art. 334:

\begin{abstract}
Art. 334. Se a petição inicial preencher os requisitos essenciais e não for o caso de improcedência liminar do pedido, o juiz designará audiência de conciliação ou de mediação com antecedência mínima de 30 (trinta) dias, devendo ser citado o réu com pelo menos 20 (vinte) dias de antecedência.

$\S 1^{\circ} \mathrm{O}$ conciliador ou mediador, onde houver, atuará necessariamente na audiência de conciliação ou de mediação, observando o disposto neste Código, bem como as disposições da lei de organização judiciária.

$\S 2^{\circ}$ Poderá haver mais de uma sessão destinada à conciliação e à mediação, não podendo exceder a 2 (dois) meses da data de realização da primeira sessão, desde que necessárias à composição das partes.

[...]

$\S 8^{\circ} \mathrm{O}$ não comparecimento injustificado do autor ou do réu à audiência de conciliação é considerado ato atentatório à dignidade da justiça e será sancionado com multa de até dois por cento da vantagem econômica pretendida ou do valor da causa, revertida em favor da União ou do Estado. (BRASIL, 2015).
\end{abstract}

No novo Código, há uma — valorização do consenso e uma preocupação em criar no âmbito do Judiciário um espaço não apenas de julgamento, mas de resolução de conflitos\| (CUNHA; AZEVEDO NETO, 2014, p. 197).

Assim, a conciliação ou mediação devem ser compreendidas como mecanismos capazes de solucionar os conflitos entre as partes, e não como uma técnica destinada a esvaziar o Judiciário, em razão da falta de estrutura e de eficiência dos órgãos julgadores.

\title{
AS GARANTIAS PROCESSUAIS NAS CONSTITUIÇÕES EUROPEIAS E LATINO AMERICANAS
}

Diversos textos constitucionais preveem a instituição de um Estado Democrático de Direito. Todavia, não basta a mera previsão no texto da Constituição, sendo necessário que esse mesmo texto, assim como o resto do ordenamento jurídico, institua mecanismos para o pleno e efetivo exercício da cidadania ${ }^{1}$.

\footnotetext{
1 Compreende-se cidadania como —deliberado vínculo jurídico-político-constitucional que qualifica o indivíduo como condutor de decisões, construtor e reconstrutor do ordenamento jurídico da sociedade política a que se filioull (LEAL, 2002, p. 150-151).
} 
Como já mencionado, a democracia não pode se limitar à vontade da maioria, mas deve permitir a inclusão de todos, com suas individualidades. Isto significa que a democracia deve estar diretamente vinculada à —prerrogativa de autoinclusão da Cidadaniall, garantindo que —cada pessoa promova sua própria inserção na ordem jurídicall (GRESTA, 2014, p. 10).

Assim, as Constituições analisadas neste trabalho caracterizam pela verdadeira pretensão de construir o Estado Democrático de Direito, trazendo não só direitos fundamentais para todos, como exemplo para as demais, mas também mecanismos de garantia desses direitos.

Induvidoso que a Constituição deve não somente tutelar determinados direitos humanos, mas como também inserir em seu texto meios de garantias para que esses direitos possam ser amplamente exercidos, ou seja, a positivação dos direitos humanos é insuficiente para assegurar -a efetividade do livre exercício de tais direitosll (BARACHO, 2006, p. 53), exigindo-se que o ordenamento jurídico também crie garantias que os tornem eficazes.

No mesmo sentido, Ronaldo Brêtas de Carvalho Dias afirma que -de nada adiantaria um extenso rol de direitos fundamentais, se mecanismos que assegurassem sua concretização também não fossem selecionados e incluídos no texto constitucionall (BRÊTAS, 2010, p. 72).

Assim, conclui-se, conforme o ensinamento de José Cirilo Vargas, que a mera previsão e proclamação dos direitos é insuficiente, vez que é preciso —dar os meios para exercê-los, para desfrutá-los\|, de modo a —afastar a ideia de mero complexo de princípios filosóficos e generosos, sem eficácia executóriall (VARGAS, 1992, p. 50).

As garantias constitucionais passam a ter grande relevância no estudo do processo, tendo em vista que várias dessas garantias, apesar de previstas no texto constitucional, possuem natureza processual, motivo pelo qual, no Estado Democrático de Direito, torna-se inviável desvincular o processo da Constituição.

Neste contexto, há duzentos anos, era aprovada a Constituição Espanhola de 1812 ou La Pepa, também conhecida como Constituição de Cádiz, em 18 de Março de 1812, pelas Cortes Gerais Extraordinárias reunidas na cidade de Cádiz, Espanha. Considerada a primeira constituição aprovada entre os países ibero-americanos, com características revolucionárias para a época e princípios consagradores do Estado de Direito e a democracia, influenciou profundamente o desenvolvimento do constitucionalismo espanhol, português e latino-americano, deixando um legado de 
inclusão política e social. A Constituição Espanhola de 1812 foi antecedida apenas pela Constituição Corsa de 1755 (a primeira efetivamente democrática), pela Constituição dos Estados Unidos da América (1787) e pela Constituição Francesa de 1791. (ESPANHA, 1912).

No Brasil, este marco constitucional apenas foi efetivamente atingido em 1988, com a promulgação da atual Constituição da República, findando um longo período ditatorial. O novo texto constitucional, em seu artigo $1^{\circ}$, reconhece o Brasil como um Estado Democrático de Direito, superando os antigos modelos de Estado, Social e Liberal, e modificando não só os limites da intervenção do Estado na esfera privada, mas também possibilitando que a atuação do Estado se tornasse a representação da vontade popular. (BRASIL, 1988).

No caso do Brasil, apesar de desde a primeira Constituição da República, promulgada em 1891, ter expressa previsão de que o texto constitucional tinha por objetivo a organização de um —regime livre e democráticoll, é certo que somente com a Constituição de 1988 foram criados mecanismos para efetivar tal promessa democrática, tendo existido, até então, um verdadeiro Estado Social, com um excesso de poderes do Estado e pouca, ou quase nenhuma, participação popular.

O mesmo se verifica na Constituição de Portugal, datada de 1974. Além de deixar claro em seu preâmbulo, a restituição aos cidadãos portugueses dos direitos e liberdades fundamentais, em razão da derrubada de um regime fascista, a Constituição Portuguesa inclui em seu texto garantias processuais como o contraditório e a ampla defesa (art. 32), o dever de fundamentar as decisões judiciais (art. 205) e o amplo acesso à jurisdição e a razoável duração do processo (art. 20). (PORTUGAL, 1974).

No mesmo sentido, a Constituição italiana de 1947, aqui incluída a título exemplificativo eis que não componente da Comunidade Ibero-Americana de Nações, trouxe uma seção específica para a regulamentação da atividade jurisdicional, iniciandose com a previsão da atuação mediante observância do devido processo legal (一 giusto processo reglato dalla leggell - art. 111), seguindo, no mesmo artigo, com a previsão das demais garantias essenciais ao processo democrático. Dispõe a Constituição que -cada processo se desenvolve pelo debate entre as partes, em condições de igualdade, perante tribunal independente e imparcial. A lei prevê a duração razoável. $\|^{2}$ (ITÁLIA, 1974).

\footnotetext{
2 No original: -Ogni processo si svolge nel contraddittorio tra le parti, in condizioni di parità, davanti a giudice terzo e imparziale. La legge ne assicura la ragionevole duratall.
} 
A abordagem das garantias processuais como garantias fundamentais também se encontra na Constituição da Espanha de 1978, que prevê o acesso à jurisdição como direito fundamental, tutelado pela ampla defesa, dispondo que -todas as pessoas têm direito a proteção efetiva dos juízes e tribunais no exercício dos seus direitos e interesses legítimos, sem que, em qualquer caso, não haja defesall ${ }^{3}$. (ESPANHA, 1978).

O mesmo dispositivo ainda prevê:

\begin{abstract}
Além disso, todos têm direito a um juiz ordinário predeterminado por lei, a defesa e a assistência por um defensor, a ser informado das acusações contra eles, a um julgamento público, sem dilações indevidas e com plenas garantias, a utilização de todos os meios de prova relevantes para a sua defesa, não se incriminar, não confessar-se culpado e a presunção de inocência. ${ }^{4}$ (ESPANHA, 1978).
\end{abstract}

Cabe aqui aclarar, interessante o posicionamento de Lenio Luiz Streck sobre a utilização da hermenêutica jurídica para intermediar o texto da lei e seu sentido. Para tanto:

na era das Constituições compromissórias e sociais, uma hermenêutica jurídica capaz de intermediar a tensão inexorável entre o texto e o sentido do texto não pode continuar a ser entendida como uma teoria ornamental do direito, que sirva tão somente para colocar _capas de sentido" aos textos jurídicos. No interior da virtuosidade do círculo hermenêutico, o compreender não ocorre por dedução ou subsunção. Conseqüentemente, o método (ou o _procedimento discursivo') sempre chega tarde, porque pressupor saberes teóricos (discursos de fundamentação) separados da realidade‘. Antes de argumentar, o intérprete já compreendeu. O uso da linguagem não é arbitrário, isto é, _a linguagem não depende de quem a usa‘ (Gadamer). A compreensão antecede qualquer argumentação, porque lhe é condição de possibilidade. Portanto, é equivocado afirmar, v.g., que o juiz primeiro decide e só depois fundamenta (justifica). Na verdade, ele só decide porque já encontrou, na antecipação de sentido, o fundamento. Mas somente é possível compreender isso a partir da admissão da tese de que a linguagem não é um mero instrumento ou uma terceira coisa' que se interpõe entre um sujeito (cognoscente) e um objeto (cognoscível). Numa palavra: o _abismo gnosiológico' que _separa' o homem das coisas e da compreensão acerca de como elas são não depende - no plano da hermenêutica jurídico-filosófica - de pontes que venham a ser construídas - paradoxalmente - depois que a travessia (antecipação de sentido) já tenha sido feita. (STRECK, 2006, p. 286).

Como exemplo, vale ainda mencionar a Constituição de Andorra de 1993, que traz as garantias fundamentais do processo em seu art. $10^{5}$, que também se encontram

\footnotetext{
${ }^{3}$ No original: -Todas las personas tienen derecho a obtener la tutela efectiva de los jueces y tribunales en el ejercicio de sus derechos e intereses legítimos, sin que, en ningún caso, pueda producirse indefensión.l ${ }^{4}$ No original: -Asimismo, todos tienen derecho al Juez ordinario predeterminado por la ley, a la defensa y

a la asistencia de letrado, a ser informados de la acusación formulada contra ellos, a un proceso público sin dilaciones indebidas y con todas las garantías, a utilizar los medios de prueba pertinentes para su defensa, a no declarar contra sí mismos, a no confesarse culpables y a la presunción de inocencia.ll

${ }^{5}$ No original: -Article 10

1. Es reconeix el dret a la jurisdicció, a obtenir d'aquesta una decisió fonamentada en Dret, i a un procés
} 
revistas no art. 19 da Constituição do Chile de $1980^{6}$, no art. 139 da Constituição

Peruana de $1993^{7}$ e no art. 29 da Constituição da Colômbia de $1991^{8}$.

Percebe-se que a inclusão no texto constitucional de diversas garantias processuais, que pretendem a efetividade dos direitos fundamentais, aproxima o processo da Constituição, tornando, ainda, o texto constitucional indispensável para o devido processo, situação esta que torna clara a denominação —modelo constitucional de processoll. (BARACHO, 1984).

\section{O PROCESSO CONSTITUCIONAL CONTEMPORÂNEO NO ESTADO DEMOCRÁTICO DE DIREITO}

Os textos constitucionais analisados no tópico anterior preveem a instauração do Estado Democrático de Direito, o que, em resumo, significa que o Estado contemporâneo fundamenta-se no exercício do poder pelo povo e limitação deste poder pelas normas do ordenamento jurídico, superando as noções de Estado Social e Estado

degut, substanciat per un tribunal imparcial predeterminat per la llei.

2.Es garanteix a tothom el dret a la defensa i a l'assistència tècnica d'un lletrat, a un judici de durada raonable, a la presumpció d'innocència, a ésser informat de l'acusació, a no confessar-se culpable, a no declarar en contra d'ell mateix i, en els processos penals, al recurs.

3.La llei regularà els supòsits en què, per garantir el principi d'igualtat, la justícia ha d'ésser gratuïta.ll (ANDORRA, 1993).

${ }^{6}$ No original: -La ley arbitrará los medios para otorgar asesoramiento y defensa jurídica a quienes no

puedan procurárselos por sí mismos. La ley señalará los casos y establecerá la forma en que las personas naturales víctimas de delitos dispondrán de asesoría y defensa jurídica gratuitas, a efecto de ejercer la acción penal reconocida por esta Constitución y las leyes. Toda persona imputada de delito tiene derecho irrenunciable a ser asistida por un abogado defensor proporcionado por el Estado si no nombrare uno en la oportunidad establecida por la ley. Nadie podrá ser juzgado por comisiones especiales, sino por el tribunal que señalare la ley y que se hallare establecido por ésta con anterioridad a la perpetración del hecho. Toda sentencia de un órgano que ejerza jurisdicción debe fundarse en un proceso previo legalmente tramitado.Corresponderá al legislador establecer siempre las garantías de un procedimiento y una investigación racionales y justos.l (CHILE, 1980).

${ }^{7} \mathrm{O}$ texto da Constituição do Peru de 1993 estabelece em seu art. 139 os princípios e direitos fundamentais da função jurisdicional, incluindo -la observancia del debido proceso y la tutela jurisdiccionall, -La motivación escrita de las resoluciones judiciales en todas las instancias, excepto los decretos de mero trámite, con mención expresa de la ley aplicable y de los fundamentos de hecho en que se sustentanll e -El principio del derecho de toda persona de formular análisis y críticas de las resoluciones y sentencias judiciales, con las limitaciones de leyll (PERU, 1993).

${ }^{8}$ No original: - El debido proceso se aplicará a toda clase de actuaciones judiciales y administrativas.

Nadie podrá ser juzgado sino conforme a leyes preexistentes al acto que se le imputa, ante juez o tribunal competente y con observancia de la plenitud de las formas propias de cada juicio. En materia penal, la ley permisiva o favorable, aun cuando sea posterior, se aplicará de preferencia a la restrictiva o desfavorable. Toda persona se presume inocente mientras no se la haya declarado judicialmente culpable. Quien sea sindicado tiene derecho a la defensa y a la asistencia de un abogado escogido por él, o de oficio, durante la investigación y el juzgamiento; a un debido proceso público sin dilaciones injustificadas; a presentar pruebas y a controvertir las que se alleguen en su contra; a impugnar la sentencia condenatoria, y a no ser juzgado dos veces por el mismo hecho. Es nula, de pleno derecho, la prueba obtenida con violación del debido proceso.ll (COLÔMBIA, 1991). 
Liberal. Portanto, entende-se por Estado Democrático de Direito aquele submetido às —nomas do direito e estruturado por leis, sobretudo a lei constitucionall, em que se estabelece uma —estreita conexão interna entre dois grandes princípios jurídicos, democracia e Estado de Direitoll (BRÊTAS, 2010, p. 54).

Ronaldo Brêtas de Carvalho Dias afirma que o Estado Democrático de Direito representa uma fusão entre o Estado de Direito e o princípio democrático e acrescenta que:

[...] essa fusão permite criar um sistema constitucional marcado de forma preponderante pela associação do poder político legitimado do povo (democracia) com a limitação do poder estatal pelas normas constitucionais e infraconstitucionais que integram seu ordenamento jurídico (Estado de Direito), sobretudo aquelas pertinentes aos direitos fundamentais. (BRÊTAS, 2010, p. 147).

No que se refere ao princípio democrático, deve-se observar que democracia remete, primariamente, à ideia —governo do povoll. Ou seja: democracia significa permitir a participação do povo, conferindo legitimidade à atuação do Estado nas esferas legislativa, administrativa e judicial, nos termos dispostos no artigo $1^{\circ}$, parágrafo único, da Constituição da República do Brasil de 1988, segundo o qual —odo o poder emana do povo, que o exerce por meio de representantes eleitos ou diretamentell. (BRASIL, 1988).

Buscando conceituar democracia, Simone Goyard-Fabre afirma que esta:

[...] define a forma de um regime que, fundando a autoridade do governo no povo, garante a presença dos governados ao exercício do poder. Por outro lado, transporta e transpõe para a esfera política o caráter conflituoso das paixões humanas, de forma tal que, no mesmo movimento que suscita a esperança da liberdade e da igualdade, faz pesar sobre a Cidade as ameaças da desrazão que o desejo insaciável do povo introduz na razão. (GOYARDFABRE, 2003, p. 13).

Assim, nessa matriz disciplinar, o poder é exercido em razão da vontade soberana do povo, que, por meio de uma série de direitos e garantias consagrados no ordenamento jurídico, também — possui direito de fiscalizar as formas de manifestação e aplicação de tal poder\| (MADEIRA, 2009, p. 22), o que garante a legitimação democrática da atuação do Estado.

É o que assevera Ronaldo Brêtas:

Tudo isso significa permanente sujeição do Estado Brasileiro ao ordenamento jurídico vigente, integrado por normas de direito (regras e princípios jurídicos), emanadas da vontade do povo, que se manifesta por meio dos seus representantes eletivos ou diretamente, por meio do plebiscito, do referendo e da iniciativa popular, motivo da menção explícita da Constituição brasileira ao princípio da reserva legal (ou princípio da prevalência da lei), como garantia fundamental das pessoas (artigo $5^{\circ}$, II,), e ao princípio da legalidade, 
estruturante do Estado de Direito brasileiro (artigo 37). (BRÊTAS, 2006a, p. 156).

Do princípio democrático ainda resulta, no âmbito jurisdicional, o dever do Estado e o direito do jurisdicionado de buscar uma resposta às suas pretensões, com a devida fundamentação, mediante a garantia de ampla participação na construção das decisões, observado, assim, o devido processo legal.

Em razão da consagração jurídico-constitucional dessa nova principiologia, o processo deve ser analisado sob uma perspectiva democrática e, por isso, é necessário romper com as teorias do processo que permitem a concepção da atividade jurisdicional como um poder do Estado, a fim de compreendê-la como um direito fundamental. Esse rompimento deve ser estabelecido, principalmente, com a Teoria do Processo como Relação Jurídica, sistematizada por Büllow, segundo a qual o processo é uma relação jurídica entre autor, réu e juiz. Tal teoria foi trazida ao Brasil por Enrico Tulio Liebman, influenciando Alfredo Buzaid na elaboração do Código de Processo Civil de 1973 e sendo acompanhada pela intitulada Escola Paulista/Instrumentalista de Processo. (BRASIL, 1973)

O Código de Processo Civil brasileiro de 1973 sofreu, ao longo dos quarenta anos de vigência, mais de sessenta e seis leis modificadoras de seu conteúdo, sendo seis na década de 70 , onze na década de 80 , vinte e duas na década de 90 , demonstrando forte produção legislativa, que resultou em uma descaracterização do principal mecanismo processual brasileiro. (BRASIL, 1973). Assim é que, a elaboração do novo Código de Processo Civil brasileiro, através da recente aprovação da Lei Federal n. 13.105/2015, encontrou sua essência fundamental na necessidade de resistematização do principal instrumento processual brasileiro. Ressalte-se ainda o aumento dos poderes instrutórios e decisórios do julgador, como exemplo a própria concessão de tutelas de evidência de ofício, tanto nas mãos do magistrado de primeiro grau, quanto do relator do processo nos tribunais, o que parece ser o tônus da nova codificação brasileira, com amplo prestígio ao princípio da celeridade e o vínculo infraconstitucional à teoria instrumentalista do processo (BRASIL, 2015), objeto principal de estudo no Instituto Brasileiro de Direito Processual (INSTITUTO, 2015a).

Para a doutrina instrumentalista, -0 conceito de jurisdição não seria jurídico, mas, político, já que ela é expressão do poder do Estadol (GONÇALVES, 2012, p. 157), fazendo com que a atividade do juiz seja influenciada por seus próprios princípios ideológicos, construída unilateralmente por sua clarividência, em uma atividade solitária 
e solipsista, o que não é compatível com a noção democrática de processo. Ou seja, ao tratar o processo como um instrumento de busca pela -paz socialll e -pela justiçall, admite-se que o magistrado se torne a figura suprema da relação processual e atue de forma discricionária e arbitrária, buscando aplicar sua própria e subjetiva noção de -justiçall, assim desconsiderando a atuação das partes/participação popular, o que não se mostra consentâneo com a atual conjuntura constitucional do processo.

Assim, referida doutrina deve ser abandonada, uma vez que, no contexto democrático, não se pode - reduzir o processo a uma relação jurídica vista como um mecanismo no qual o Estado-juiz implementa sua posição de superioridade de modo que o debate processual é relegado a segundo planoll (NUNES, 2011, p. 49).

Como superação da mencionada teoria, na tentativa de ampliar a participação das partes no processo jurisdicional, surge a teoria estruturalista ${ }^{9}$ de Elio Fazzalari, segundo o qual o processo seria o procedimento em contraditório, cuidando Fazzalari de diferenciar procedimento de processo e de elevar o contraditório à condição de pressuposto essencial para a existência de processo. (FAZZALARI, 2006).

Dessarte, esclarece Fazzalari:

Existe, em resumo, o _processo“, quando em uma ou mais fases do iter de formação de um ato é contemplada a participação não só - e obviamente - do seu autor, mas também dos destinatários dos seus efeitos, em contraditório, de modo que eles possam desenvolver atividades que o autor do ato deve determinar, e cujos resultados ele pode desatender, mas não ignorar. (FAZZALARI, 2006, p. 120).

A teoria de Fazzalari é de grande relevância para a compreensão do processo democrático, uma vez que inclui o contraditório como parte do conceito de processo, concluindo que não há processo, mas tão somente procedimento, quando ausente o contraditório. A relevância dos estudos de Fazzalari não está somente na diferenciação entre processo em procedimento, mas também na inclusão da participação das partes como elemento essencial para que haja processo.

Percebe-se que, assim, iniciam-se os estudos do Direito Processual a partir de uma perspectiva democrática, fazendo com que a atividade jurisdicional deixasse de ser controlada pelo julgador, incluindo, agora, a participação e fiscalização dos interessados.

\footnotetext{
9 Ronaldo Brêtas de Carvalho Dias e Carlos Henrique Soares afirmam que a teoria elaborada por Fazzalari é denominada estruturalista, porque trata o processo como - procedimento que se desenvolve dentro da estrutura dialética e constitucionalizada do contraditório\| (SOARES; BRÊTAS, 2011, p. 103).
} 
A atividade jurisdicional não pode, portanto, ser reduzia a mera —vontade do intérprete (julgar conforme sua consciência), como se a realidade fosse reduzida à sua representação subjetivall, tendo em vista que a função do julgador se limita a ser -0 aplicador da lei como intérprete das articulações lógico-jurídicas produzidas pelas partes construtoras da estrutura procedimental\| (LEAL, 2010, p. 63).

Complementando a teoria de Fazzalari, a teoria constitucionalista do processo, marco teórico do presente trabalho, não afasta a alegação de ser o processo um procedimento em contraditório, mas acrescenta que o processo seria também uma garantia de exercício dos direitos fundamentais, o que lhe concede uma perspectiva constitucional.

\title{
É o que considera Ronaldo Brêtas de Carvalho Dias:
}

[...] a teoria estruturalista de Fazzalari carece de alguma complementação pelos elementos que compõe a teoria constitucionalista, porque a inserção do contraditório no rol das garantias constitucionais decorre da exigência lógica e democrática da co-participação paritária das partes, no procedimento formativo da decisão jurisdicional que postulam no processo, razão pela qual conectada está à garantia também constitucional da fundamentação das decisões jurisdicionais centrada na reserva legal, condição de efetividade e legitimidade democrática da atividade jurisdicional constitucionalizada. (BRÊTAS, 2010, p. 91).

A teoria constitucionalista do processo tem por base o estudo dialógico participativo, principal foco de pesquisa na Escola Mineira de Processo, conforme destaque no Instituto Mineiro de Direito Processual (INSTITUTO, 2015b). Para tanto, comentário de Dierle Nunes:

\begin{abstract}
A percepção democrática do direito rechaça a possibilidade de um sujeito solitário captar a percepção do bem viver em sociedade altamente plurais e complexas e, no âmbito jurídico, a aplicação do direito e/ou o proferimento de provimentos, fazendo-se necessária a percepção de uma procedimentalidade na qual todos os interessados possam influenciar na formação das decisões. Assim, toda decisão deve ser resultado de um fluxo discursivo balizado por um procedimento embasado nos princípios fundamentais (processo) que permita uma formação processual de todo exercício do poder. (NUNES, 2011, p. 203).
\end{abstract}

A origem dos estudos acerca do processo em conjunto com o texto constitucional remonta ao mexicano Hector Fix-Zamudio ${ }^{10}$ e ao uruguaio Eduardo Couture $^{11}$.

\footnotetext{
${ }^{10}$ Fix-Zamudio, em sua obra -Constituición y Proceso Civil en Latinoaméricall, de 1974, analisou a relevância que as garantias fundamentais passaram a ter nos estudos de direito processual, concluindo que, diante da existência de numerosas disposições constitucionais acerca dos direitos das partes no processo civil, torna-se impossível desvincular qualquer legislação processual de tais direitos fundamentais. (FIX-ZAMUDIO, 1974).
} 
Em homenagem a memória de Eduardo J. Couture, o Instituto Iberoamericano de Direito Processual foi fundado em Montevidéu, nas Primeiras Jornadas LatinoAmericanas de Direito Processual, realizadas em 1957, representando importante associação civil nos estudos da democratização do Direito Processual. (INSTITUTO, 2015c).

Diante dos avançados estudos do Processo constitucionalizado, José Alfredo de Oliveira Baracho afirma que -0 direito processual tem linhagem constitucional, circunstância que dá maior significação à proteção efetiva dos direitos processuais, em todas as instâncias\| (BARACHO, 2006, p. 14), ainda acrescentando que -0 processo constitucional visa tutelar o princípio da supremacia constitucional, protegendo os direitos fundamentais\| (BARACHO, 2006, p. 95).

Desse modo, tem-se que as normas processuais devem observar a supremacia da Constituição $^{12}$, uma vez que o processo é considerado uma importante garantia constitucional. Por isso, as normas processuais, como já demonstrado, surgem consolidadas nos textos das Constituições do moderno Estado Democrático de Direito, —sufragando os direitos das pessoas obterem a função jurisdicional do Estado, segundo a metodologia normativa do processo constitucional\| (BRÊTAS, 2010, p. 92).

Conforme informa Baracho, - 0 modelo constitucional do processo civil assentase no entendimento de que as normas e os princípios constitucionais resguardam o exercício da função jurisdicional\| (BARACHO, 2006, p. 15), o que leva ao entendimento de que a jurisdição é direito fundamental, e que, por consequência, seria inviável compreender o processo como mero instrumento de sua realização, devendo ser compreendido como forma de garantia não só deste, mas de todos os direitos fundamentais positivados pelo texto constitucional.

Em consonância com tais apontamentos, André Del Negri esclarece que -são as partes processuais que orientam a fundamentação da decisão (relação jurídica entre

\footnotetext{
11 Apesar de verificar que Eduardo Couture ainda considera o processo como um instrumento da jurisdição, seguindo a orientação da Teoria do Processo como Relação Jurídica de Büllow, é possível constatar em seus estudos um esboço de um direito processual constitucional, a partir da ideia de que o processo deve ser estruturado por meio de um método dialético, permitindo que as partes e o juiz realizem o debate, tendo esclarecido Couture que a atividade jurisdicional se —serve da dialética porque o princípio da contradição é o que permite, por confrontação dos opostos, chegar à verdade\| (COUTURE, 2008, p. 44).

${ }^{12}$ Segundo José Afonso da Silva, Supremacia da Constituição significa que esta se encontra no vértice do sistema jurídico conferindo validade a todos os atos do Estado realizados conforme reconhecido no texto constitucional, na proporção em que os poderes estatais forem distribuídos (SILVA, 2007, p. 45). Afirma também José Cirilo Vargas que a —constituição é que forma o arcabouço jurídico-político de uma Naçãol, traçando -os pressupostos de todos os setores da ordem jurídicall, inclusive do Processo. (VARGAS, 1992, p. 57).
} 
normas), e não mais uma vontade emanada da esfera solitária de convicção do juiz\|l (DEL NEGRI, 2011, p. 87). Assim, percebe-se a clara vinculação do princípio do contraditório ao princípio da fundamentação das decisões, como informam Débora Fioratto e Ronaldo Brêtas:

\begin{abstract}
No Estado Democrático de Direito, o contraditório deve ser compreendido como princípio de influência e de não surpresa, tornando-se base para o princípio da fundamentação da decisão e para o exercício do controle da argumentação utilizada pelo juiz. Se houver a restrição ou a supressão da garantia constitucional do contraditório, certamente, haverá a violação da garantia constitucional da fundamentação das decisões. Ao passo que se o princípio da fundamentação das decisões for respeitado, o contraditório também foi respeitado no trâmite processual. (FIORATTO; BRÊTAS, 2010, p. 132).
\end{abstract}

Daí que, observada a teoria constitucionalista contemporânea do processo, colhe-se que o processo, em seus novos contornos teóricos na pós-modernidade, apresenta-se como instituição constitucionalizada que, pela principiologia constitucional do devido processo (que abarca os princípios da reserva legal, da ampla defesa, da isonomia e do contraditório) converte-se em direito-garantia. O conceito contemporâneo de Estado Democrático de Direito exige que o legislador, nas sociedades Políticas Democráticas de Direito, uma vez eleito, submeta-se aos princípios do Processo como instituição jurídica balizadora da soberania popular e da cidadania, cujos fundamentos se assentam no instrumento da jurisdição constitucional e esta como atividade judicatória dos juízes, de forma legal, preexistente e básica, como única fonte do poder constituinte. Assim, não é demais reprisar que o devido processo constitucional tem por fundamento garantir o princípio da supremacia constitucional, possibilitando a efetiva tutela, proteção e fomento dos direitos fundamentais. Importante ressaltar que o processo constitucional demanda pressupostos essenciais, dentre eles: o direito à celeridade dos processos, a razoável duração dos pleitos, e as formas de controle constitucional (preventivo, repressivo, direto, repressivo indireto e ocasional); que não podem ser confundidos com diminuição ou eliminação das garantias processuais constitucionais (contraditório, ampla defesa, duplo grau de jurisdição, fundamentação das decisões, direito de prova, instrumentalidade das formas, presença de advogado, dentre outros), sob pena de ferir o princípio do Estado Democrático de Direito.

À jurisdição constitucional define-se como atividade jurisdicional exercida pelo Estado com o objetivo de tutelar o princípio da supremacia da Constituição e a proteção aos direitos fundamentais da pessoa humana nela estabelecidos. Meta possível a partir do controle (difuso e concentrado) de constitucionalidade das leis ordinárias e dos atos 
estatais que estejam em contrariedade aos preceitos constitucionais; perfilhados no exame da matéria jurídico-constitucional em consenso à fixação de uma estrutura de garantias (devido processo legal, recurso de amparo, recurso de proteção, recurso constitucional, ação direta de inconstitucionalidade, mandado de segurança, habeas corpus, habeas data, mandado de injunção, ação popular, cada um dentro de suas especificidades), com mecanismos efetivos, que proteja e assegure a efetividade daqueles direitos.

Assim, a inclusão no texto constitucional brasileiro, em 1988, de diversas garantias processuais, que pretendem a efetividade dos direitos fundamentais, aproxima o processo da Constituição, tornando, ainda, o texto constitucional indispensável para o devido processo, situação esta que torna clara a denominação —modelo constitucional de processoll. (BARACHO, 1984).

\section{A ISONOMIA COMO CONDIÇÃO ESSENCIAL PARA A REALIZAÇÃO DA MEDIAÇÃO NO CONSTITUCIONALISMO CONTEMPORÂNEO}

A isonomia consiste na garantia constitucional de que as partes serão tratadas no procedimento de forma igualitária, sem que se limite indevidamente a participação de nenhuma delas e também sem que nenhuma parte tenha qualquer privilégio em detrimento da outra.

A isonomia possui estreita correlação com o princípio do contraditório, tendo em vista que -não há contraditório desenvolvido sem observância da simétrica paridade\| (FONSECA, 2000, p. 19), ou seja, a igualdade de tratamento processual das partes é essencial para garantir o efetivo contraditório, -é essa igualdade de oportunidade que compõe a essência do contraditório enquanto garantia de simétrica paridade de participação no processo\| (GONÇALVES, 2012, p. 109).

Nesse sentido, —pode-se afirmar que não há contraditório onde não há simétrica paridade entre as partes, onde não há igualdade temporal de os litigantes influírem na causa; consequentemente, o processo não se instaura, mas apenas o procedimentoll (FONSECA, 2000, p. 20).

Fiz-Zamudio afirma que a igualdade processual pode ser concebida de formas diversas, de acordo com o momento jurídico-político, destacando que após a segunda guerra predomina uma concepção socializadora do direito, cuidando os ordenamentos jurídicos latino-americanos de garantir uma igualdade real entre as partes e não 
meramente formal como ocorre em um regime individualista e liberal (FIX-ZAMUDIO, 1974, p. 64).

Segundo Rosemiro Pereira Leal, no Estado Democrático de Direito, garante-se -a isonomia argumentativo-procedimental na defesa e reconhecimento de direitos\|, não se tratando somente de um reconhecimento de um direito à diferença, mas sim de uma —igualdade procedimental (isonomia) como pressuposto da construção e aplicação normativall, capaz de tornar os —diferentes iguais em direitos fundamentais\| (LEAL, 2005, p. 79).

Define-se, assim, que a isonomia é - princípio-norma que rege a atuação dos sujeitos do processo quanto à igualdade argumentativa na formação do discurso estrutural do procedimento de produção e aplicação do direito\| (LEAL, 2005, p. 81).

\section{A INOBSERVÂNCIA DA CIDADANIA NO PROCEDIMENTO DE MEDIAÇÃO}

Tecidas as considerações iniciais sobre a mediação e sobre o instituto processual da isonomia, cumpre analisar o conceito de cidadania no Estado Democrático de Direito, de modo a investigar se a utilização desse método alternativo de resolução de conflitos seria adequado para promover o exercício da cidadania.

Para tal análise, é necessário ressaltar que, para que seja a mediação incluída como fase processual, é indispensável que, em tal procedimento observe todos os princípios processuais, dentre os quais se inclui a isonomia no constitucionalismo contemporâneo.

Somente é possível que as partes cheguem a um acordo, caso ambas estejam em condição de igualdade. Segundo Rosemiro Pereira Leal, -não há transação entre pessoas em desigualdade econômica estrutural\| (LEAL, 2014, p. 263).

Assim, somente há que se falar em efetividade da mediação, caso garantida a isonomia entre as partes, o que, obviamente, nem sempre é possível.

Como assevera Roberta Maia Gresta, -os excluídos têm negada sua dignidade humana, uma vez que em relação a eles é aceitável a não aplicação de direitos fundamentais\| (GRESTA, 2014, p. 53), isso porque a cidadania não é automaticamente outorgada a todos os cidadãos.

Segundo Gresta, a teorização da democracia —assimila uma diretriz de exclusão política e social que demanda esclarecimento e enfrentamento para a construção de uma 
processualidade democrática calcada na premissa de autoinclusãol (GRESTA, 2014, p. $11)$.

Para Rosemiro Pereira Leal, cidadania é o —deliberado vínculo jurídico-políticoconstitucional que qualifica o indivíduo como condutor de decisões, construtor e reconstrutor do ordenamento jurídico a que se filioull (LEAL, 2002, p. 150-151).

Assim, entende-se que, para que a mediação possa ser um meio efetivo de resolução de conflitos, é necessários que aqueles envolvidos estejam em uma condição paritária de exercício da cidadania. Ou seja, somente após a autoinclusão democrática, de forma simétrica, de todos os indivíduos, a fim de que exerçam a cidadania, será possível utilizar a mediação como mecanismo alternativo ao processo.

Percebe-se, por fim, que -0 congestionamento dos tribunais tem ensejado a adoção de um grande número de medidas de restrição de acessoll, as quais tem ocorrido -sem respeitar as bases processuais constitucionais necessárias, que imporiam a busca de uma eficiência sem desrespeitar as garantias processuais constitucionais que asseguram a legitimidade da formação da decisão em uma renovada concepção do Estado Constitucional\| (NUNES; et al, 2011, p. 63).

\section{CONSIDERAÇÕES FINAIS}

Da teoria constitucionalista do processo, colhe-se que o processo, em seus novos contornos teóricos na pós-modernidade, apresenta-se como instituição constitucionalizada que, pela principiologia constitucional do devido processo (que abarca os princípios da reserva legal, da ampla defesa, da isonomia e do contraditório) converte-se em direito-garantia. O conceito contemporâneo de Estado Democrático de Direito exige que o legislador, nas sociedades Políticas Democráticas de Direito, uma vez eleito, submeta-se aos princípios do Processo como instituição jurídica balizadora da soberania popular e da cidadania, cujos fundamentos se assentam no instrumento da jurisdição constitucional e esta como atividade judicatória dos juízes, de forma legal, preexistente e básica, como única fonte do poder constituinte. Assim, não é demais reprisar que o devido processo constitucional tem por fundamento garantir o princípio da supremacia constitucional, possibilitando a efetiva tutela, proteção e fomento dos direitos fundamentais. Importante ressaltar que o processo constitucional demanda pressupostos essenciais, dentre eles: o direito à celeridade dos processos, a razoável duração dos pleitos, e as formas de controle constitucional (preventivo, repressivo, 
direto, repressivo indireto e ocasional); que não podem ser confundidos com diminuição ou eliminação das garantias processuais constitucionais (contraditório, ampla defesa, duplo grau de jurisdição, fundamentação das decisões, direito de prova, instrumentalidade das formas, presença de advogado, dentre outros), sob pena de ferir o princípio do Estado Democrático de Direito.

Diante das considerações tecidas no texto, é possível perceber que a instauração do Estado Democrático de Direito ocasionou a mudança da matriz disciplinar que rege a atuação estatal, incluindo a atividade jurisdicional.

Desse modo, a Jurisdição passa a ser um direito fundamental, cujo exercício deve ser democratizado pelos países ibero-americanos, o que somente é possível por meio da adequada compreensão do princípio do contraditório, utilizando como marco teórico a Teoria Constitucionalista do Processo. Ao compreender o contraditório somente como um direito de manifestação das partes interessadas, não se permite a devida democratização do processo e da atividade jurisdicional, tendo em vista que não afasta a discricionariedade e arbitrariedade do julgador e nem mesmo inclui como motivação dos atos jurisdicionais os argumentos apresentados pelas partes.

Diante das considerações tecidas, torna-se possível perceber que a promulgação do novo Código de Processo Civil brasileiro, trouxe ao processo mecanismos alternativos de resolução de conflitos, buscando alcançar a rápida solução dos litígios.

O Processo deve servir como uma instituição de cidadania democrática, inconcebível a formulação de decisões sem observância da técnica normativa estrutural, pautada principalmente no paradigma constitucional do processo, em que devem ser observadas as razões de justificação deduzidas pelas partes, no procedimento em contraditório, pela simétrica paridade, em torno das questões de fato e de direito processual ou material discutidas nos autos.

A concretização da democracia exige não só que os interessados tenham o direito de se manifestar, mas sim que essa manifestação seja considerada pelo ente estatal, seja capaz de construir o provimento final. Assim, nos atos jurisdicionais, somente é possível falar em concretização da democracia se os provimentos forem proferidos mediante a análise de todos os argumentos apresentados pelas partes interessadas, sendo vedada a decisão em dissonância com a manifestação de qualquer das partes ou que represente, em verdade, a opinião pessoal do julgador.

Todavia, os mecanismos de mediação elencados no novo CPC brasileiro não cumprem sua função de autoinclusão democrática, uma vez que não possibilitam o 
pleno exercício das garantias fundamentais do processo, consagrado no modelo de Constituições latino-americanas e europeias democráticas, permitindo que sejam realizados acordos entre partes que se encontram em condições não-isonômicas, causando, sempre ou quase sempre, prejuízo à parte considerada hipossuficiente.

\section{REFERÊNCIAS}

ANDORRA, Constituición del Principado de Andorra. 1993. Disponível em:

<http://www.consellgeneral.ad/fitxers/documents/constitucio/const-cast>. Acesso em: 17 jan. 2016.

BARACHO, José Alfredo de Oliveira Baracho. Direito Processual Constitucional: Aspectos Contemporâneos. Belo Horizonte: Fórum, 2006.

BARACHO, José Alfredo de Oliveira. Processo constitucional. Rio de Janeiro: Forense, 1984.

BRASIL, Constituição de 1988. Constituição da República Federativa do Brasil de 1988.

Disponível em: <http://www.planalto.gov.br/ccivil_03/constituicao/constituicao.htm>. Acesso em: 17 jan. 2016.

BRASIL, Lei n. 13.105, de 16 de março de 2015. Código de Processo Civil. Disponível em: <http://www.planalto.gov.br/ccivil_03/_Ato2015-2018/2015/Lei/L13105.htm\#art1046>. Acesso em: 17 jan. 2016.

BRASIL, Lei n. 5.869, de 11 de janeiro de 1973. Institui o Código de Processo Civil.

Disponível em: <http://www.planalto.gov.br/ccivil_03/leis/15869compilada.htm>. Acesso em: 17 jan. 2016.

BRÊTAS, Ronaldo de Carvalho Dias. As reformas do código de processo civil e o processo constitucional. In: BRÊTAS, Ronaldo de Carvalho Dias; NEPOMUCENO, Luciana Diniz (Coords.). Processo civil reformado. Belo Horizonte: Del Rey, 2006.

BRÊTAS, Ronaldo de Carvalho Dias. Direito à Jurisdição Eficiente e Garantia da Razoável Duração do Processo no Estado Democrático de Direto. In: GALUPPO, Marcelo Campos (Org.). O Brasil que Queremos: Reflexões sobre o Estado Democrático de Direito. Belo CONPEDI LAW REVIEW | OÑATI, ESPANHA | v. 2 | n. 2 | p. 40 - 61 | JAN/JUN. 2016 
Horizonte: PUC Minas, 2006.

BRÊTAS, Ronaldo de Carvalho Dias. Processo Constitucional e Estado Democrático de Direito. Belo Horizonte: Del Rey, 2010.

CHILE, Constituición Política de la República. 1980. Disponível em:

<http://www.oas.org/dil/esp/constitucion_chile.pdf>. Acesso em: 17 jan. 2016.

COLÔMBIA, Constituición Política de Colômbia. 1991. Disponível em: < http://wsp.presidencia.gov.co/Normativa/Documents/ConstitucionPoliticaColombia_20100810. pdf>. Acesso: 17 jan. 2016.

COUTURE, Eduardo. Introdução ao Estudo do Processo Civil: Discursos, Ensaios e Conferências. Trad. Hiltomar Martins Oliveira. Belo Horizonte: Líder, 2008.

CUNHA, Leonardo Carneiro da; AZEVEDO NETO, João Luiz Lessa de. A Mediação e a Conciliação no Projeto do novo CPC: Meios Integrados de Resolução de Disputas. In: FREIRE, Alexandre; DANTAS, Bruno; NUNES, Dierle; DIDIER JUNIOR, Fredie; MEDINA; José Miguel Garcia; FUX, Luiz. CAMARGO; Luiz Henrique Volpe. OLIVEIRA, Pedro Miranda de. Novas Tendências do Processo Civil: Estudos sobre o Projeto do Novo Código de Processo Civil. Salvador: Juspodivm, 2014.

DEL NEGRI, André . Processo Constitucional e decisão interna corporis. Belo Horizonte: Fórum, 2011.

ESPANHA, Constituição de 1978. Disponível em: < http://www.tribunalconstitucional.es/es/constitucion/Paginas/ConstitucionIngles.aspx > Acesso em: 17 jan. 2016.

ESPANHA, La Constitución Española de 1918. Biblioteca Virtual Miguel de Cervantes. Disponível em: <http://www.cervantesvirtual.com/portales/constitucion_1812/>. Acesso em: 17 jan. 2016.

FAZZALARI, Elio. Instituições de Direito Processual. Trad. Elaine Nassif. Campinas: Bookseller, 2006.

FIORATTO, Débora Carvalho; BRÊTAS, Ronaldo de Carvalho Dias. A Conexão entre os Princípios do Contraditório e da Fundamentação das Decisões no Estado Democrático de 
Direito. Revista Eletrônica do Curso de Direito - PUC Minas Serro. V. 01, 2010.

FIX-ZAMUDIO, Hector. Constituición y Proceso Civil em Latinoamérica. México: Instituto de Investigaciones Juridicas, 1974.

FONSECA, Rodrigo Rigamonte. Isonomia e Contraditório na Teoria do Processo. In: LEAL, Rosemiro Pereira (coord.) Estudos Continuados de Teoria do Processo. Porto Alegre: Síntese, 2000. v. 1.

GOLÇALVES, Aroldo Plínio. Teoria do Processo e Técnica Processual. Belo Horizonte: Del Rey, 2012.

GOYARD-FABRE, Simone. O que é democracia?. Trad. de Cláudia Berliner. São Paulo:

Martins Fontes, 2003.

GRESTA, Roberta Maia. Introdução aos Fundamentos da Processualidade Democrática. Rio de Janeiro: Lumen Juris, 2014.

INSTITUTO Brasileiro de Direito Processual. IBDP. Disponível em:〈http://www.direitoprocessual.org.br/> Acesso em: 17 jan. 2016.

INSTITUTO Iberoamericano de Direito Processual. IIDP. Disponível em: $<$ http://iibdp.org/index.php/pt/espa nol.html>. Acesso em: 17 jan. 2016.

INSTITUTO Mineiro de Direito Processual. IMDP. Disponível em:〈www.imdp.com.br/home>. Acesso em: 17 jan. 2016.

ITÁLIA, Constituição de 1947. Disponível em:

<http://www.quirinale.it/qrnw/statico/costituzione/pdf/Costituzione.pdf >. Acesso em: 17 jan. 2016.

LEAL, Rosemiro Pereira Leal. Relativização Inconstitucional da Coisa Julgada. Belo Horizonte: Del Rey, 2005.

LEAL, Rosemiro Pereira. Teoria Geral do Processo: Primeiros Estudos. Rio de Janeiro: Forense, 2014.

LEAL, Rosemiro Pereira. Teoria Geral do Processo: primeiros estudos. 9. ed. Rio de Janeiro: Forense, 2010. 
LEAL, Rosemiro Pereira. Teoria processual da decisão jurídica. São Paulo: Landy, 2002.

MADEIRA, Dhenis Cruz. Processo de Conhecimento e Cognição. Curitiba: Juruá, 2009.

NUNES, Dierle José Coelho. Processo Jurisdicional Democrático. Curitiba: Juruá, 2011.

NUNES, Dierle; et al. Curso de Direito Processual Civil: Fundamentação e Aplicação. Belo Horizonte: Fórum, 2011.

PERU, Constituición Política Del Perú. 1993. Disponível em:

<http://www4.congreso.gob.pe/ntley/Imagenes/Constitu/Cons1993.pdf>. Acesso em: 17 jan. 2016.

PORTUGAL, Constituição de 1974. Disponível em:

<http://www.parlamento.pt/Legislacao/Paginas/ConstituicaoRepublicaPortuguesa.aspx> .

Acesso em: 17 jan. 2016.

SILVA, José Afonso da. Curso de Direito Constitucional Positivo. São Paulo: Malheiros, 2007.

SOARES, Carlos Henrique; BRÊTAS, Ronaldo de Carvalho Dias. Manual Elementar de Processo Civil. Belo Horizonte: Del Rey, 2011.

STRECK, Lenio Luiz. Verdade e consenso: constituição, hermenêutica e teorias discursivas. Rio de Janeiro: Lumen Juris, 2006.

VARGAS, José Cirilo. Processo Penal e Direitos Fundamentais. Belo Horizonte: Del Rey, 1992.

VEZZULA, Juan Carlos. Teoria e prática da mediação. Curitiba: IMAB, 1998. 